\title{
Goodbye and thank you
}

\section{Leo van de Putte}

The year 1999 was a landmark year for the European league Against Rheumatism (EULAR) and BMJ Publishing Group: the Annals of the Rheumatic Diseases (ARD), the world's oldest English rheumatology journal, became the official journal of EULAR, from then on being co-owned by both organisations. This marriage has proven to be a success story; the growing importance and influence of EULAR in the field of rheumatology in its broadest sense being mirrored in a very well kept and managed journal.

It has been a great experience and honour for me to have been the first editor of the journal in its new role, starting in July 1999. From then on there have been quite a few changes. A very important one was that the manuscript handling and processing became totally electronic, allowing for a substantial increase in efficiency and speed. In addition, the Online First facility of the journal now ensures an extra speeding-up of getting accepted papers into the public

Correspondence to: Leo van de Putte, UMC Nijmegen, Nijmegen, PO Box 9101, 6500 HB, The Netherlands; I. vandeputte@reuma.umcn.nl domain, usually in only a few weeks after acceptance.

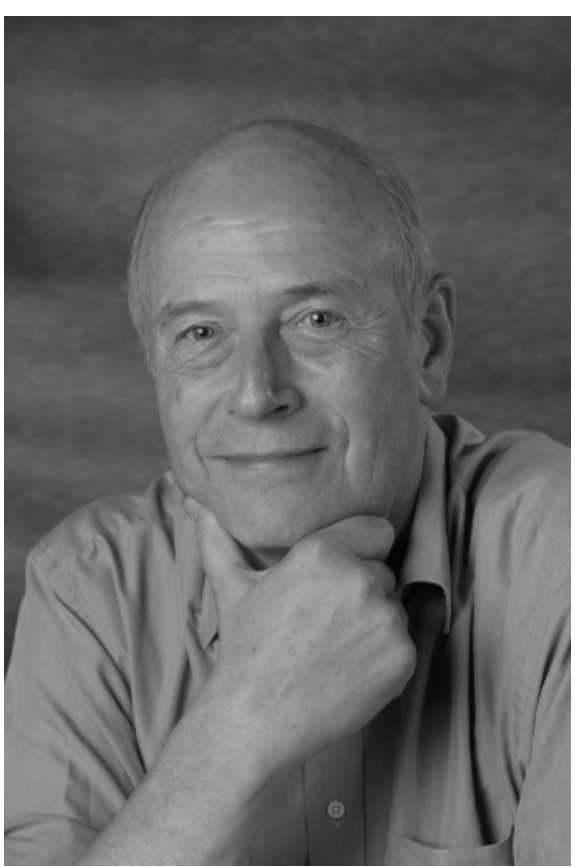

In the years since 1999 the number of submissions tripled, the quality of papers improved and the impact of the journal definitely increased. The latter is reflected in a sharp rise in Impact Factor, being around 6 in the last few years.

The performance of a journal like ARD is down to teamwork. As departing editor, I'm quite aware that I owe much to all those who made their best efforts for the journal: authors, reviewers, and the editorial team, including associate editors and board; the pleasant and professional working with friends at BMJ Publishing Group and EULAR. And last but certainly not least, our editorial assistant, Christine JanssenSeijkens, whom I enjoyed so much working with and who compensated so well for many of my shortcomings. Fortunately, she will continue with her work for the journal.

It is a particular pleasure for me to pass on the editorship of the journal to my colleague and friend, Professor Tore Kvien, who will certainly contribute greatly to the further growth and excellence of the journal. The handover will be as of 1 April 2008.

I wish him and his team a safe journey into the future and the success that ARD deserves.

Competing interests: None.

Accepted 17 January 2008

Ann Rheum Dis 2008;67:437. doi:10.1136/ard.2008.088690

\section{The new Editor greets you}

\section{Tore K Kvien}

It is an honour, an opportunity and a challenge to take over the position of editor of the Annals of Rheumatic Diseases (ARD). Professor Leo van de Putte has, during his almost nine-year editorship, developed ARD to become the leading rheumatology journal in Europe.

The connection with the European League Against Rheumatism (EULAR) has facilitated a huge readership and the shared ownership of the journal between EULAR

Correspondence to: Tore K Kvien, Diakonhjemmet Hospital, Oslo N-0319, Norway; t.k.kvien@medisin.uio.no and BMJ Publishing Group has created opportunities for fast and effective communication of science in rheumatology.

Will there be changes in the journal with the new editor?

The only visual change in this issue is many new names among the Associate Editors, in the Editorial Board, and on the Advisory Committee. All previous members who have completed their term have made tremendous contributions to the journal. Many of the new members of the Editorial Boards represent a new generation of young rheumatologists and scientists who will further enhance and

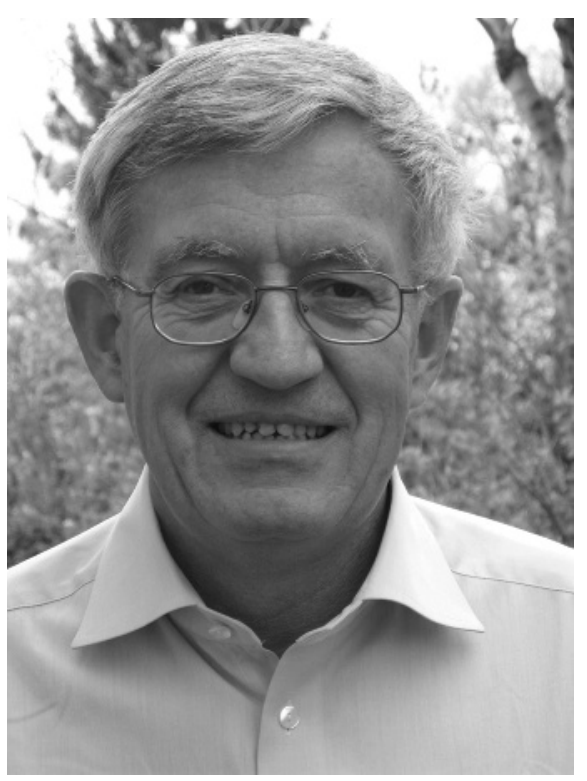

